\title{
How are map-based decisions influenced by uncertainty visualization in risky and time-critical situations?
}

\author{
Michelle Korporaal $^{\mathrm{a}}$ and Sara Irina Fabrikant $\mathrm{b}^{*}$ \\ ${ }^{a}$ Skyguide, michelle.korporaal@skyguide.ch \\ ${ }^{b}$ Department of Geography and Digital Society Initiative, University of Zurich, sara.fabrikant@geo.uzh.ch \\ * Corresponding author
}

Keywords: Time pressure, uncertainty visualization, decision making process, decision outcomes

\section{Extended Abstract:}

Most of our daily activities in a highly mobile digital information society require timely spatial decision making. Much of such decision-making is supported by map displays on various devices and with different modalities. Spatial information visualized on maps, however, is always subject to a multitude of uncertainties. If space-time decisionmakers are not informed about potential uncertainties inherent to maps, misleading, false, or at worst, life-threatening outcomes might result from the map-based decision making process. Therefore, data uncertainties should be communicated to decision-makers (Hope and Hunter, 2007), especially when they are made with limited time resources (Riveiro et al., 2014), and/or decision outcomes can have dramatic consequences (Ruginski et al., 2016). We thus wished to empirically study how data uncertainty visualized in maps might influence the process and outcomes of spatial decision making (Kübler et al., 2017), especially when made under time pressure in risky situations (Wilkening and Fabrikant, 2011). Although there is very little empirical evidence from prior uncertainty visualization research that considered decision time constraints, we hypothesized that uncertainty visualization would also have an effect under time critical and complex decision contexts.

We report on a mixed factorial (2x2) map-based experiment to investigate whether and how the depiction of uncertainty in map displays (within-subject: with vs. without uncertainty) used in time-critical decision situations (between subject: with vs. without decision time constraints) might influence complex spatial decision making processes supported with maps (dependent variable: eye movement patterns), and respective decision outcomes (dependent variable: accuracy of response). For this we developed an extended version of a helicopter landing scenario in mountainous terrain for our study (Wilkening and Fabrikant, 2011). We told participants to imagine being helicopter pilots on a rescue mission. We told participants in a training session (and had them practise the task in a warm-up trial) that there are several requirements that needed to be considered to safely land a helicopter in such emergency situations (AuLaV, 2014). We asked them to safely land a helicopter on one of six potential landing spots marked on a map (Figure 1) to rescue a person in need. Map stimuli were based on randomly chosen and anonymized locations in Switzerland with varying terrain. The person to be rescued was always marked near the center of the map; in a zone unsuitable for land a helicopter. We systematically controlled four criteria that needed to be considered by decision makers: (1) slope categories $\left({ }^{\circ}\right.$ ), including slope uncertainty, (2) distance (m) to an air aviation obstacle, (3) distance (m) to a ski lift, and (4) distance (m) to the person to be rescued. We developed eight map stimuli, and a ninth for the warm-up trial. To increase the map set, we additionally rotated and flipped the eight original maps to generate 16 map stimuli in total. We randomized the labeling of the potential landing spots, to avoid potential response bias. Prior to the main experiment, we ran an online study (with the identical test scenario) recruiting 11 participants (females: 6 , males: 7; 34,8 yrs. on average) by Email, with broadly varying backgrounds, to empirically identify a suitable decision time limit for the main experiment, and to assess the suitability of the decision scenario. We also tested two map-inherent (within-subject) uncertainty depiction methods, already proposed in the literature: hatching density and point density textures (Retchless and Brewer 2016, Johannsen and Fabrikant, 2018). Based on the pilot study results, we chose the point-density pattern (Figure 1) for the main experiment, as it not only yielded faster decision times, but it was also preferred by participants. Based on participants' average decision times, we also set the time limit to $25 \mathrm{~s}$ for the main experiment.

We then invited 34 participants (females: 18, males: 16; 27,7 yrs. on average) to our eye-tracking laboratory at the Geography Department of the University of Zurich for the controlled portion of the study. They were again recruited broadly, without any specific training or background relevant for the chosen multivariate decision making scenario. Participants were randomly assigned to the time-pressure group, and they did not differ in spatial ability, assessed with the paper-folding test (Ekstrom et al., 1976). 


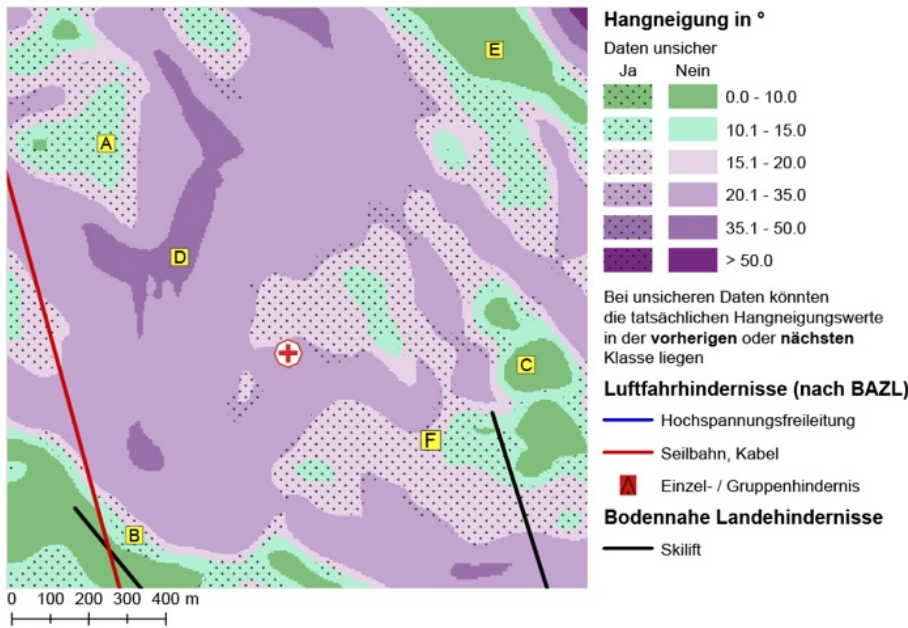

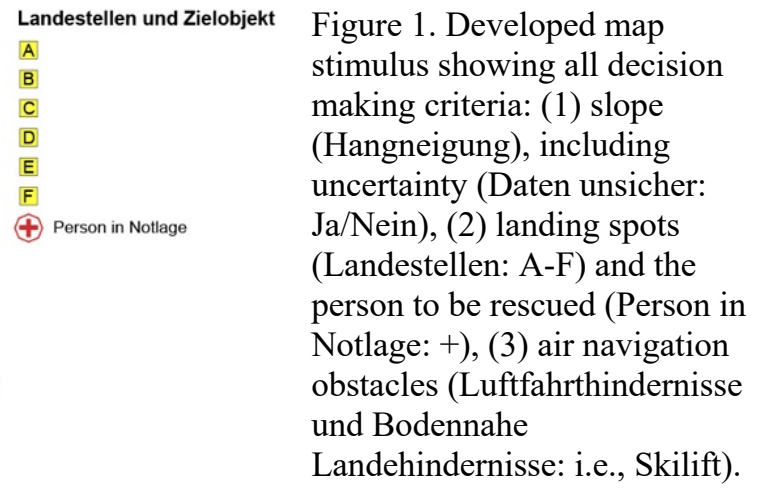

Figure 1. Developed map stimulus showing all decision uncertainty (Daten unsicher: $\mathrm{Ja} / \mathrm{Nein}$ ), (2) landing spots (Landestellen: A-F) and the person to be rescued (Person in Notlage: +), (3) air navigation und Bodennahe Landehindernisse: i.e., Skilift).

As hypothesized, we find that visualized slope uncertainty information influences both, participants' decision making processes, and the decision outcomes, depending on whether the available decision time is constrained. We are thus able to replicate prior own uncertainty visualization research that did not consider any decision time constraints (Kübler et al, 2017), and map-based decision making under time pressure without any uncertainty depictions (Wilkening and Fabrikant, 2011). Without depiction of slope uncertainty, participants selected landing spots that were closer to the person to be rescued, but not necessarily at locations with ideal slope conditions. For decisions supported by visualized slope uncertainty, participants opted for the safer landing location, but further away as necessary from the person to be rescued. Safer in this case means that participants who were not under decision time constraints chose to land the helicopter at a location which they knew would be suitable for landing in any case.

We interpret this result pattern with loss aversion (Kahnemann \& Tversky, 1979). Participants weighed the landing spot in an uncertain slope zone that could potentially yield the loss of lives more negatively, as the gain of being closer to the person to be rescued. Replicating Kübler et al. (2017) we also find that the depiction of uncertainty in maps modifies the to date under-researched map-based decision-making processes. Contrasting prior cartographic research, though, participants without time pressure took longer for their decisions when slope uncertainty was depicted on the maps. The collected eye movement data reveals that maps were indeed viewed in different ways, depending on whether slope uncertainty was depicted. This sheds new light on how decision time matters in map-based decision making (Wilkening and Fabrikant, 2011). As decision outcomes are similar across the two decision time groups, the visualization of uncertainty, ultimately, had the same effect. Taking advantage of eye movement recordings, we are thus able to provide new insights in how humans arrive at complex map-based decisions when uncertainty is depicted on maps, especially when they are used in time-critical and risky decision making contexts.

(References are added on a third page for completeness) 


\section{References}

Aussenlandeverodnung (AuLaV) (2014). Verordnung über das Abfliegen und Landen mit Luftfahrzeugen ausserhalb von Flugplätzen vom 14. Mai 2014, Verordnung 748.132.3.

Ekstrom, R. B., French, J. W., Harman, H. H., Dermen, D. (1976). Manual for kit of factor-referenced cognitive tests, Educational testing service, Princeton, New Jersey.

Hope, S., \& Hunter, G. J. (2007). Testing the effects of positional uncertainty on spatial decision-making. International Journal of Geographical Information Science, 21(6), 645-665.

Johannsen, I. M., Fabrikant, S. I., Evers, M. (2018). How do texture and color communicate uncertainty in climate change map displays? In: Winter, S., Griffin, A., Sester; M. (eds). 10th International Conference on Geographic Information Science (GIScience), Leibniz International Proceedings in Informatics (LIPiCS), No. 37; 37:1-37:6.

Kahneman, D., \& Tversky, A. (1979). Prospect theory: An analysis of decision under risk. Econometrica, 47(2), 263292.

Kübler, I., Richter, K.-F., Fabrikant, S.I., (2017). Visualization of risk and uncertainty to communicate avalanche hazard: An Empirical Study. Proceedings, 28th International Cartographic Conference, International Cartographic Association, Jul. 2-7, 2017, Washington, D.C. USA.

Retchless, D. P., \& Brewer, C. A. (2016). Guidance for representing uncertainty on global temperature change maps. International Journal of Climatology, 36(3), 1143-1159.

Riveiro, M., Helldin, T., Falkman, G., Lebram, M. (2014). Effects of visualizing uncertainty on decision-making in a target identification scenario. Computers and Graphics, 41(1), 84-98.

Ruginski, I. T., Boone, A. P., Padilla, L. M., Liu, L., Heydari, N., Kramer, H. S., Hegarty, M., Thompson, W. B., House, D. H., Creem-Regehr, S. H. (2016). Non-expert interpretations of hurricane forecast uncertainty visualizations. Spatial Cognition \& Computation, 16(2), 154-172.

Wilkening, J., \& Fabrikant, S. I. (2011). How do decision time and realism affect map-based decision making? Conference on Spatial Information Theory (COSIT 2011), Proceedings, Lecture Notes in Computer Science 6899. Egenhofer, M. (Ed.) Springer, Berlin, Germany: 1-19 